\title{
水相中无催化剂条件下直接合成苯并噻吩吡咯烷酮
}

\author{
邢慧聪解沛忠*
}

(南京工业大学化学与分子工程学院 南京 211816)

\section{Construction of Benzothiophene Fused Pyrrolidone in Water under Catalyst-Free Conditions}

\author{
Xing, Huicong Xie, Peizhong* \\ (School of Chemistry and Molecular Engineering, Nanjing Tech University, Nanjing 211816)
}

利用简便易得的原料, 在环境友好溶剂中, 以高原 子/步骤经济性构筑目标化合物是现代有机合成的追求 目标之一 ${ }^{[1]}$. 苯并噻吩骨架在生物活性分子及药物分子 中分布广泛 ${ }^{[2]}$, 使相关有机功能材料具备独特的性能 ${ }^{[3]}$. 因此, 苯并噻吩及相关骨架的构筑方法研究受到广泛关 注. 通常情况下, 苯并噻吩构筑依赖过渡金属 $(\mathrm{Pd} / \mathrm{Cu}$ 、 $\mathrm{Au}$ 等)催化的环化反应 ${ }^{[4]}$. König 报道 ${ }^{[5]}$ 的有机光催化策 略实现了苯并噻吩的高效合成, 遗憾的是反应的原子经 济性较低. 最近, Procter 课题组 ${ }^{[6]}$ 巧妙利用苯环 $\mathrm{C}-\mathrm{H}$ 键 官能团化实现了一锅多步法合成苯并噻吩，同时避免了 过渡金属使用. 然而该方法需要以化学计量添加剂和氧 化剂为代价. 基于制药及材料等相关领域的需求, 环境 友好条件下, 发展绿色高效的苯并噻吩及相关骨架构筑 方法是一项十分重要也是具有挑战性的课题.

近年来, 多米诺反应为多种环类化合物的合成提供 了高原子经济性和步骤经济性策略 ${ }^{[7]}$. 天津理工大学化 学化工学院孟祥太课题组 ${ }^{[8]}$ 致力于杂环化合物的绿色多 米诺构筑方法研究, 在无金属条件下实现了以硫代靛红 为原料的多样性导向合成, 用于多类含硫环状化合物的 高效构筑(图 1a). 近日, 该团队 ${ }^{[9]}$ 在水相条件下, 利用简 便易得的原料, 通过三组分多米诺反应高效合成了一系 列苯并噻吩吡咯烷酮化合物(图 1b). 值得注意的是, 该 反应无需使用催化剂/添加剂, 可以将硫代靛红、4-氯乙 酰乙酸乙酯、伯胺快速转化为目标化合物, 也是首例在 水相中实现多官能团化苯并噻吩吡咯烷酮构筑. 该团队 以胺对 $\mathrm{C}-\mathrm{S}$ 键的活化为突破口, 巧妙构筑了 $\mathrm{C}-\mathrm{S} 、 \mathrm{C}$ $-\mathrm{C}$ 及两种类型的 $\mathrm{C}-\mathrm{N}$ 化学键; 使反应具有很高的步 骤经济性的同时还得到了较高的目标产物收率. (a) Meng's strategy towards benzothiophene fused framwork

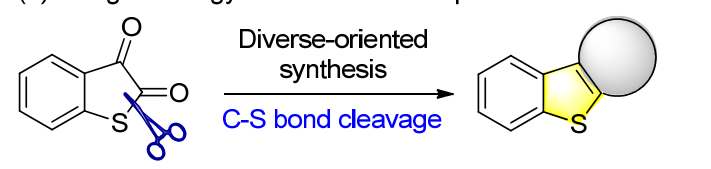

(b) This work

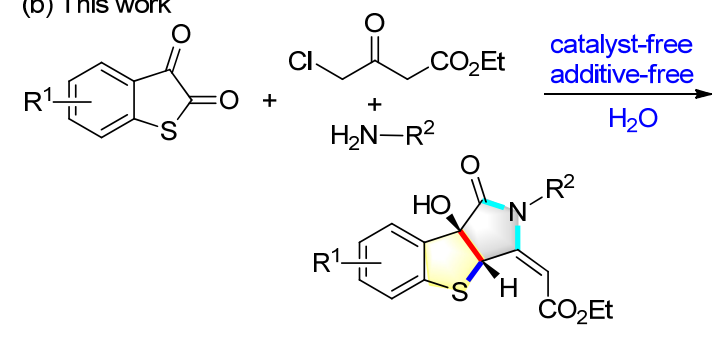

图 1 水相中直接合成苯并噻吩吡咯烷酮

Figure 1 Construction of benzothiophene fused pyrrolidone in water

水是一种廉价、安全和环境友好的理想溶剂. 因此, 使用水作为反应介质在绿色合成及生物医药研究中受 到广泛的关注 ${ }^{[10]}$. 研究表明, 在有机合成中, 水能够加 快某些反应的反应速率. 孟祥太团队着重研究了水相中 该反应的效果. 作者研究发现，相对于多类有机溶剂， 水能给出较好的反应效果. 在 $120{ }^{\circ} \mathrm{C}$ 条件下仅仅 $4 \mathrm{~h}$, 目标产物能以 $89 \%$ 的收率被分离得到.

在最优条件基础上, 作者对反应的底物适用性进行 了详细研究. 对于胺类化合物, 茮胺的苯环上无论是吸 电子基团还是给电子基团，反应都能顺利进行(图 2, 4a 4h). 值得注意的是, 当苯环上带有吸电子基团时 $(4 \mathrm{~g}, 4 \mathrm{~h})$, 会生成一部分脱羧产物 5 . 芳环上取代基的位 置对反应影响不大 $(\mathbf{4 i} \sim \mathbf{4 m})$, 即使是 2 -吡啶芐胺也能很 好地进行反应, 只是收率略低. 随后, 作者又研究了硫

* Corresponding author. E-mail: peizhongxie@njtech.edu.cn. Published online December 31, 2020. 
代靛红苯环上不同取代基对反应的影响. 取代基的电子 效应和空间效应对反应的影响都是有限的，无论是大位 阻的基团、强吸电子基团，还是强给电子基团，该反应 都能很好地进行 $(\mathbf{4 n} \sim \mathbf{4 v})$. 芳环上有拉电子基团时, 反 应也有脱羧产物 5 生成. 除了茮胺之外, 苯胺、有特定 位阻的脂肪族伯胺都能很好地参与反应 $(\mathbf{4 w} \sim \mathbf{4 z})$, 进一 步证实了该反应的适用范围广泛，官能团兼容性好.

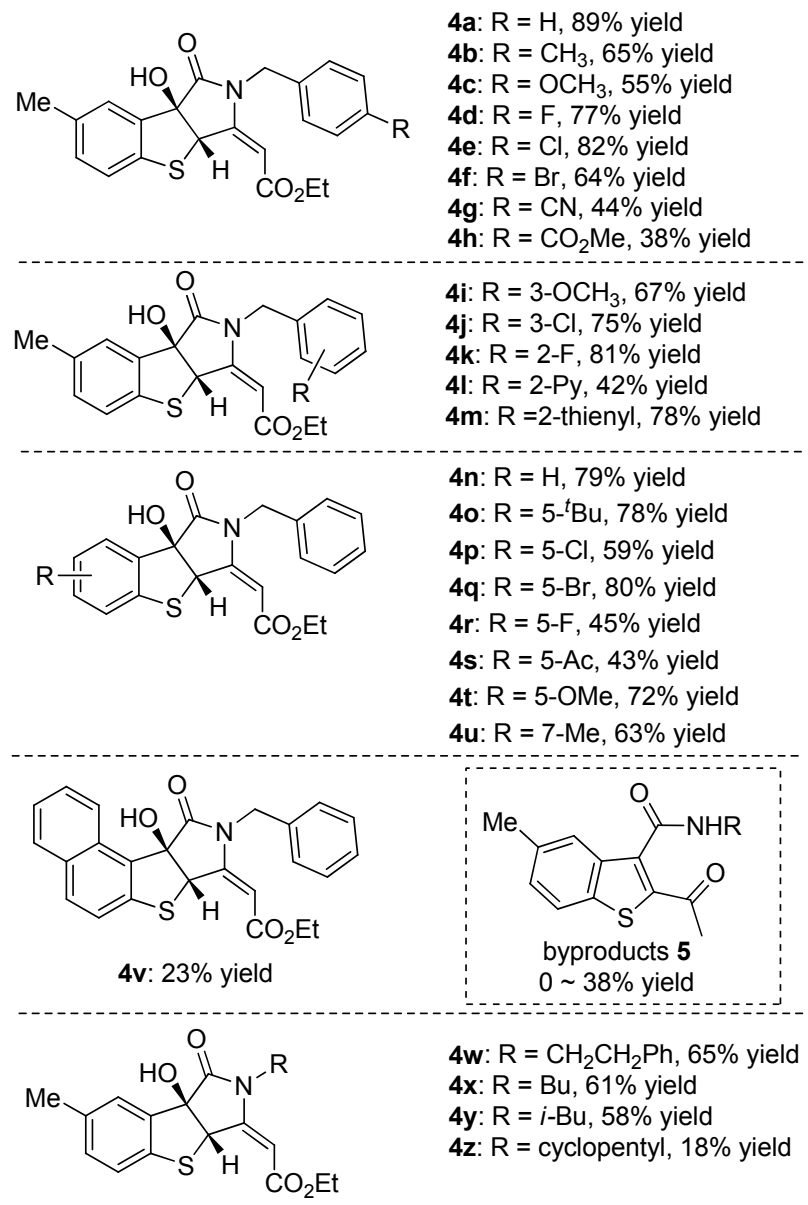

图 2 底物适用性研究

Figure 2 Substrate scope of this protocol

在研究反应底物适用性基础上, 作者对产物 4 进行 了转化研究. 研究发现, 对甲苯磺酸可以将 4 脱水转化 成苯并噻吩; 使用 $m$-CPBA 可以将产物中的硫氧化为 砜. 随后, 作者还将反应规模扩大到克级, 收率依然达 到了 $72 \%$.

在实验基础上，作者通过密度泛函理论(DFT)对该 反应机理进行了研究. 首先, 茮胺作为亲核试剂, 通过 加成-消除过程对 $\mathrm{C}-\mathrm{S}$ 键进行活化, 生成酰胺中间体 A. 中间体 $\mathbf{A}$ 随后和 4-氯乙酰乙酸乙酯发生亲核取代反 应, 构筑了 $\mathrm{C}-\mathrm{S}$ 化学键, 经过硫的烷基化过程生成中 间体 B. 随后，与硫相近的亚甲基在分子内对羰基进行 亲核加成, 构筑了 $\mathrm{C}-\mathrm{C}$ 化学键, 实现了五元环的构建
(C). 然后，中间体 $\mathbf{C}$ 中的 $\mathrm{NH}$ 对来自另一侧的羰基进行 亲核加成，构建第二个五元环吡咯烷酮。该过程是整个 反应的决速步骤，水分子参与该反应过程并对 $\mathrm{C}-\mathrm{N}$ 键 的形成起到明显的促进作用，该过程也很好地解释了副 产物 $\mathbf{5}$ 的生成. 最后 $\mathbf{D}$ 通过分子内脱水生成目标产物.

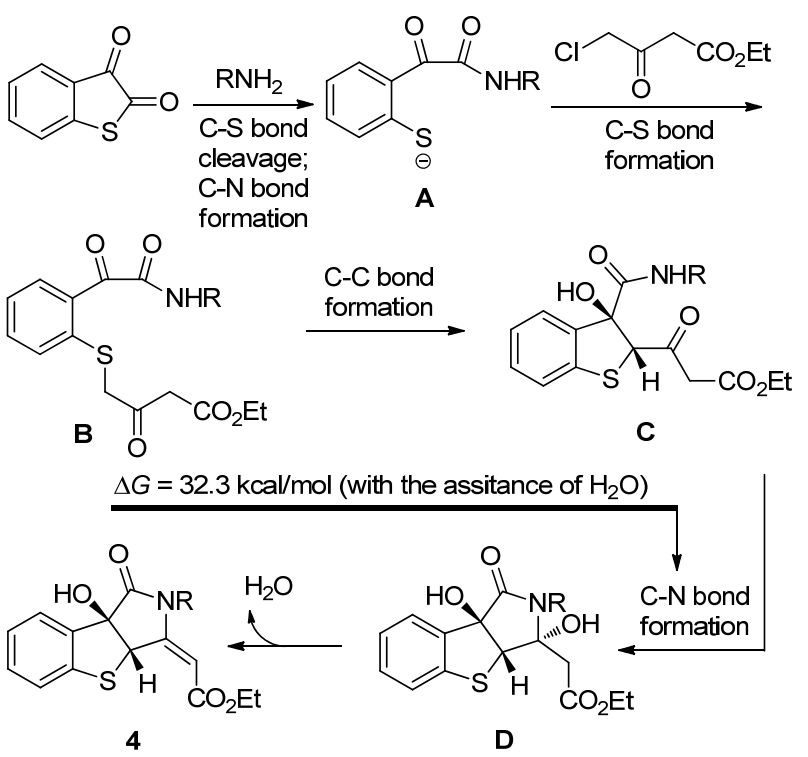

图 3 推测的反应机理

Figure 3 Proposed reaction mechanism

综上所述, 孟祥太课题组巧妙地以胺对 $\mathrm{C}-\mathrm{S}$ 键的 活化为突破口，通过多米诺过程高效构筑了 $\mathrm{C}-\mathrm{S} 、 \mathrm{C}-$ $\mathrm{C}$ 及两种类型的 $\mathrm{C}-\mathrm{N}$ 化学键, 使反应具有很高的步骤 经济性. 同时, 使用水作为溶剂, 将反应的污染降到更 低，以中等到较高的收率得到苯并噻吩吡咯烷酮化合 物. 通过 DFT 计算对反应机理进行了阐释. 该研究对绿 色有机合成研究、苯并噻吩相关生物活性分子的构架新 方法研究有重要启发意义, 同时也对推动硫代靛红的新 反应研究打下了坚实的基础.

\section{References}

[1] Xie, P.; Wang, J.; Liu, Y.; Fan, J.; Wo, X.; Fu, W.; Sun. Z.; Loh, T. P. Nat. Commun. 2018, 9, 1321.

[2] Li, L.; Chang, L.; Pellet-Rostaing, S.; Liger, F.; Lemaire, M.; Buchet, R.; Wu, Y. Bioorg. Med. Chem. 2009, 17, 7290.

[3] Takimiya, K.; Osaka, I.; Mori, T.; Nakano, M. Acc. Chem. Res. 2014, 47, 1493.

[4] Nakamura, I.; Sato, T.; Yamamoto, Y. Angew. Chem., Int. Ed. 2006, $45,4473$.

[5] Hari, D. P.; Hering, T.; König, B. Org. Lett. 2012, 14, 5334.

[6] Yan, J.; Pulis, A. P.; Perry, G. J. P.; Procter, D. J. Angew. Chem., Int. Ed. 2019, 58, 15675 .

[7] Huang, H.-M.; Garduno-Castro, M. H.; Morrill, C.; Procter, D. J. Chem. Soc. Rev. 2019, 48, 4626.

[8] Shen, J.; Yang, Y.; Hou, X.; Zeng, W.; Yu, A.; Zhao, X.; Meng, X. Org. Biomol. Chem. 2018, 16, 3487.

[9] Shen, J.; Yu, A.; Zhang, L.; Meng, X. Green Chem. 2020, 22, 6798.

[10] Kobayashi, S.; Manabe, K. Acc. Chem. Res. 2002, 35, 209.

$(\mathrm{Lu}, \mathrm{Y}$. 